\title{
Effect of stall design on dairy calf transition to voluntary feeding on an automatic milk feeder after introduction to group housing
}

\author{
Tanya R. Wilson, ${ }^{*} \dagger^{1}$ Stephen J. LeBlanc, ${ }^{*} \dagger$ Trevor J. DeVries, $\dagger \ddagger$ and Derek B. Haley ${ }^{*} \dagger^{1}$ \\ *Department of Population Medicine, Ontario Veterinary College, \\ †Campbell Centre for the Study of Animal Welfare, and \\ ‡Department of Animal Bioscience, University of Guelph, Guelph ON, N1G 2W1, Canada
}

\section{ABSTRACT}

Automatic milk feeders (AMF) for young dairy calves are widely used in the dairy industry. These feeders are thought to have benefits for calf health and welfare and may reduce labor required for feeding; however, little is known about how calves adapt to feeding with AMF. The objective of this study was to observe the effects of feeding stall design on calves learning to use the AMF. The hypothesis was that solid side stalls, compared with steel bar stalls, would result in a longer latency to approach and feed from the AMF without assistance. A total of 147 Holstein calves (80 male and 67 female) were enrolled at $4 \mathrm{~d}$ of age, introduced to a group pen, and, at the same time, trained on an AMF. For training, calves were allowed to suck on the trainer's fingers and guided to the teat. Calves were allocated to 1 of 2 stall designs at the pen level, depending on which treatment cohort they were born into, either with steel bar stall walls $(\mathrm{n}=46$ male, 34 female calves) or with solid side stall walls $(\mathrm{n}=34$ male, 33 female calves). For $72 \mathrm{~h}$ after introductory training on the AMF, data from the feeders were collected and calf behavior was monitored by video. Outcomes measured included latency to first voluntary visit to the feeder and to first feeding, time spent in the feeder, amount of milk consumed over $72 \mathrm{~h}$, number of retraining sessions required (retrained if $<2 \mathrm{~L}$ was consumed every $12 \mathrm{~h}$ ), and exploratory behavior, such as sniffing and licking of the feeder. Data were analyzed using mixed effects linear regression models or a Poisson model for the outcome of retraining. For certain outcomes the effects of stall design interacted with difficulty of training (willingness to enter feeder and drink); for the $38 \%$ of calves that were scored as moderately difficult to train on a scale of easy, moderate, or difficult, treatment (stall

\footnotetext{
Received October 17, 2017.

Accepted January 28, 2018.

${ }^{1}$ Corresponding authors: twilso04@uoguelph.ca and dhaley@ uoguelph.ca
}

design) differences were detected. These calves took $2 \times$ longer to lick or bite toward the nipple, $2 \times$ longer to first voluntarily feeding, and consumed less milk over $72 \mathrm{~h}$ following training when trained on the steel bar stall design. These results suggest simple features of a stall may influence how quickly calves learn to use an AMF, but that the influence of stall wall design was affected by how easy calves were to train on the feeder upon initial introduction, which may depend in part on certain aspects of calf temperament. For many calves, solid side stalls at an AMF resulted faster in adaption than the steel bar stalls.

Key words: dairy calves, automatic milk feeder, stall, learning

\section{INTRODUCTION}

Several studies have documented the use of automatic milk feeders (AMF) for rearing calves on dairy farms (Vasseur et al., 2010; Jorgensen et al., 2017; MedranoGalarza et al., 2017). Several questions exist about how best to manage the systems to optimize calves' adaption to them, and so promote health, growth, and labor efficiencies. Calves typically spend a period of time housed individually before moving to group housing with the AMF, and need to adjust to new social and physical environments.

Fujiwara et al. (2014) investigated whether keeping calves in pairs versus individual housing before introduction to the group pen, $6 \mathrm{~d}$ after birth, was associated with adaption to AMF. Overall, those authors found no difference between individually or pair-housed calves. However, only $27 \%$ of all calves drank voluntarily from the feeder within $24 \mathrm{~h}$ and a general decline in milk intake was noted for the first few days after introduction to the group pen, with only $69 \%$ of calves consuming milk on their first voluntary visit to the AMF. This adaption period, with the decreased milk intake as well as the stress of joining a new social group, could potentially put calves at risk for health issues (de Passillé et al., 2014). Jensen (2007) also found that calves introduced 
$\mathbf{a}$

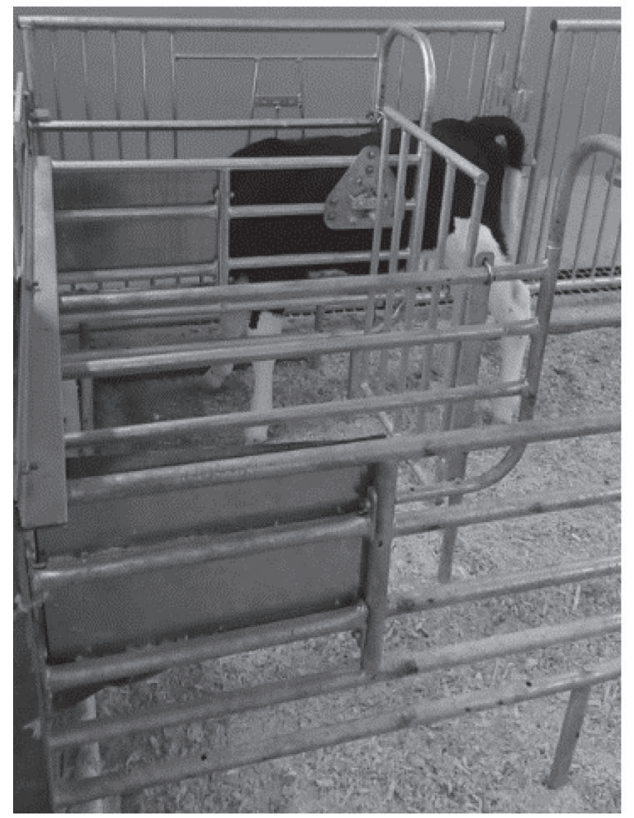

b

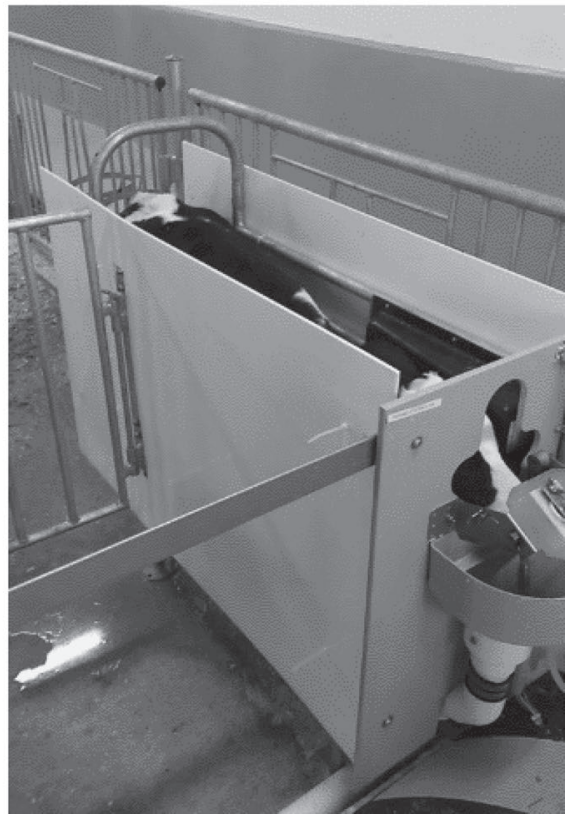

Figure 1. Photo of automated milk feeders (AMF) with (a) steel bar sides and (b) solid sides made of plastic. Photos were taken at the University of Guelph Dairy Research and Innovation Facility, Elora, Ontario, Canada.

at a younger age of 6 compared with $14 \mathrm{~d}$ required more assistance and had greater difficulty adapting to the AMF after introduction. However, a recent study by Abdelfattah et al. (2018) did not find cortisol changes related to age at grouping despite behavior differences between calves grouped at various ages (e.g., differences in cross-sucking behavior, displacements at the feeder, vocalizing); therefore, minimizing the time it takes for calves to adapt may help improve their welfare.

It is possible that some physical features of AMF may also have an influence on calf adaption to them. Physical differences exist between the design of the automated feeders that are commercially available (e.g., DeLaval, 2016; Lely, 2016). These include the placement and position of the teat within the feeder and whether calves have to flip it upwards to drink (e.g., DeLaval Inc., Tumba, Sweden), the construction material and size of the stall, and in some cases the feeder may be installed on a different floor level than the group pen, requiring calves to step up when entering the feeder. None of these features, to our knowledge, have been investigated to determine whether they affect calves learning to use the feeder. Commonly used stall designs include a steel bar style (see Figure 1a), which permits calves visual contact with the group while they feed. Another is a solid side style (see Figure $1 b$ ), where calves are unable to see in or out of the feeder stall. Researchers have previously demonstrated that competitive behavior in dairy calves is reduced by using longer stall wall lengths (Jensen et al., 2008) as well as when using a closing gate at the rear of the feeding stall (Weber and Wechsler, 2001). We aimed to investigate whether type of stall would affect behavior other than just competitive behavior of calves, but if it might affect how quickly they adapt to this type of feeding system. Previous research suggests calves learn better when they are housed with other calves (Costa et al., 2014; Miller-Cushon and DeVries, 2016) and, by applying learning theory (Gleitman et al., 2011), that calves learn by observing one another; thus, it seems plausible that calves may learn to use an AMF better when they can see other calves using it.

The objective of our study was to compare the influence of 2 different AMF stall wall designs on how quickly calves learned to use the feeder. We hypothesized that calves trained on the steel bar stall feeder would adapt more quickly because they are able to see other calves using the feeder.

\section{MATERIALS AND METHODS}

\section{Animals, Housing, and Feeding}

A total of 147 calves (80 male and 67 female) were enrolled in the study and trained on the AMF. Calves were enrolled if they were able to stand and drink from 
a bottle within the first $4 \mathrm{~d}$ of life and were not ill when introduced to the group pen. Calves were excluded from the final analysis if they failed to drink voluntarily within the 72-h observation period or became severely ill and had to be removed from the group. Data from 117 calves, 65 male and 52 females, were used in the final data analysis. Calves were born and kept at the University of Guelph Livestock Research and Innovation Centre-Dairy Facility (Elora, ON, Canada). All animals were managed according to standard operating procedures of the facility, in accordance with guidelines set by the Canadian Council of Animal Care (CCAC, 2009) and as approved by the University of Guelph's Animal Care Committee (Animal Use Protocol ID \#3477).

Sample size was calculated to detect a difference of 6 $\mathrm{h}$ in latency to first voluntary feeding with a standard deviation of $2 \mathrm{~h}$, a $95 \%$ confidence interval, and $80 \%$ power (WINPEPI; Abramson, 2006). A difference of 6 $\mathrm{h}$ between treatment groups was deemed relevant because this could make a difference in the frequency of training sessions a producer has to provide per day. To detect this difference, a sample size of 114 calves was needed, with 57 calves in each treatment group.

All calves were born in individual calving pens and given 2 meals of colostrum, totaling a minimum of 4 $\mathrm{L}$ within $24 \mathrm{~h}$ of birth, the first meal being given as soon as possible after the calf was born. The maximum time between birth and first colostrum via bottle feeding was $7 \mathrm{~h}$. Information on time of colostrum feeding, amount fed and quality of colostrum, as measured by a colostrometer, were recorded. All calves were administered $1.5 \mathrm{~mL}$ of Dystosel (Zoetis Inc., Parsippany, NJ) on the first day after birth.
Calves were housed in 1 of 4 identical calf rooms (see Figure 2). All calves were moved to individual calf pens within each room within $12 \mathrm{~h}$ of birth. Individual pens were $1.67 \times 1.51 \mathrm{~m}$ (length $\times$ width $)$ and bedded using wood shavings. Individual pens were located in a line adjacent to the group pen with the automatic milk feeder. Individual pens were removable and the group pen measured $9.07 \times 4.98 \mathrm{~m}$ without any individual pens in place and $9.07 \times 3.30 \mathrm{~m}$ when 6 individual pens were located along one side. Calves in individual pens were able to have visual, auditory, and limited physical contact with other calves in the group pen and adjacent individual pens. While in individual pens, calves were fed $2 \mathrm{~L}$ of milk replacer $3 \times / \mathrm{d}$ by bottle (at approximately 0700,1300 , and $1900 \mathrm{~h}$ ), totaling $6 \mathrm{~L} / \mathrm{d}$. A ratio of $150 \mathrm{~g}$ of milk replacer to $1 \mathrm{~L}$ of water was fed; the same replacer and concentration was used in the bottles and the AMF. The milk replacer (Grober, Cambridge, ON, Canada) contained $26 \% \mathrm{CP}$ and $18 \%$ fat. Once on the AMF, calves were allowed to feed a maximum of $2 \mathrm{~L} /$ meal and were entitled to a new meal every 2 $\mathrm{h}$, therefore allowing a maximum potential intake of 24 $\mathrm{L} / 24 \mathrm{~h}$ for the first $27 \mathrm{~d}$ on the feeder.

\section{Introduction to the AMF}

On the fourth day of life (calf born on d 0) calves were moved into the group pen and walked immediately to the AMF for training (CF 1000+ CS Combi; DeLaval Inc.). One AMF station was in each group pen, it required calves to enter and register their ear tag at the radio-frequency identification detector to obtain a milk meal. A minimum group size of 2 was used so that each calf was introduced to a pen with at least 1 calf who

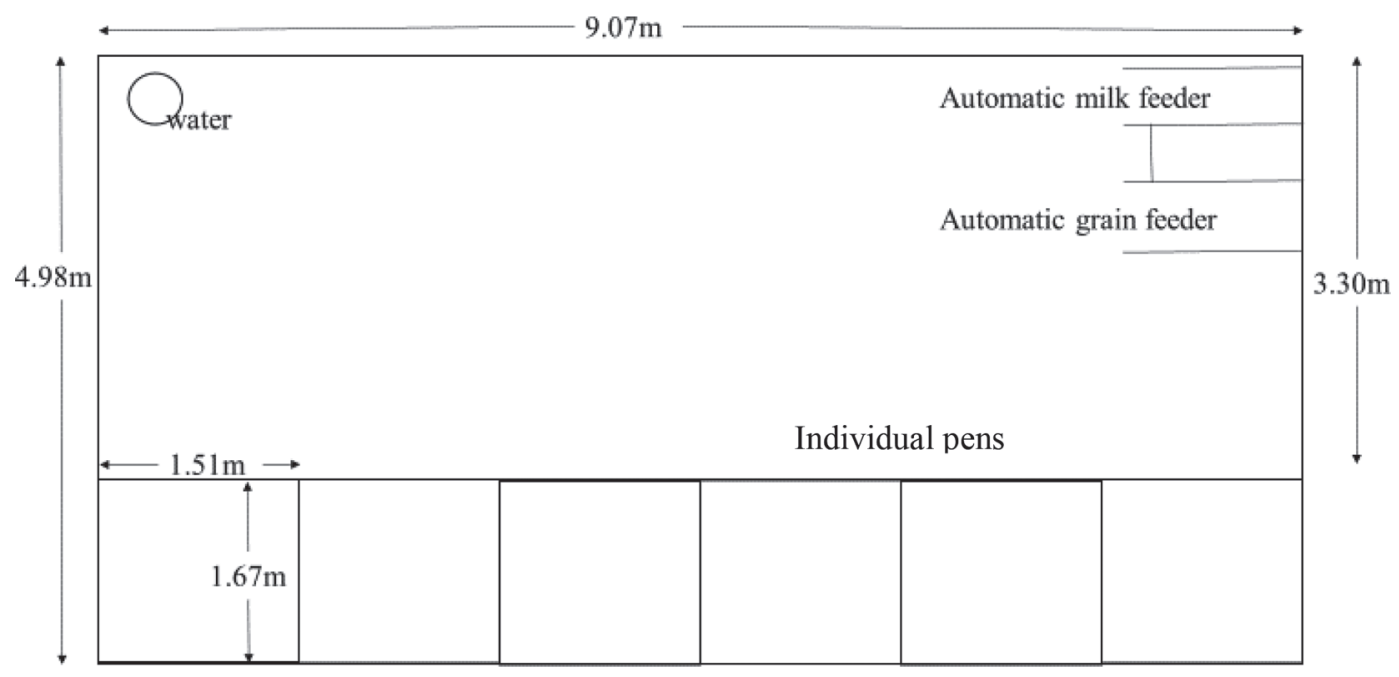

Figure 2. Diagram of the rooms housing calves fed by automated milk feeder (AMF), comparing solid versus steel bar sides on the AMF stall. Rooms 1 and 3 were identical and were mirror images of rooms 2 and 4 . 
was experienced at using the AMF. A maximum group size of 16 calves was used; the mean group size when a new calf was trained on the feeder was $8.82( \pm 3.70$, $\mathrm{SD})$. All calves were moved into the group pen and trained at $0800 \mathrm{~h}$, approximately $12 \mathrm{~h}$ after their last meal. Calves were trained by opening the gate between the individual and group pen and leading the calf into the group area by allowing it to suck on the trainer's fingers. All calves were trained by the same individual. Gentle pushing from behind was used if necessary. Calves were led immediately to the feeder, guided to the location of the teat, and allowed to consume a meal of $2 \mathrm{~L}$ of milk replacer. As each calf was moved into the feeding stall, the nipple, which was naturally positioned perpendicular to the floor to facilitate drainage, was rotated by the researcher to a position horizontal with the floor, in which milk could be consumed. The trainer would allow calves to try and flip the nipple themselves so they could learn for future feedings. Calves were kept in the feeder until they had consumed their full 2-L meal allotment, or until $15 \mathrm{~min}$ had passed with the calf not showing interest in or willingness to consume more milk. The calf was then left alone to exit the feeder on their own.

Milk consumption from the feeder was checked every day at 0800 and $2000 \mathrm{~h}$. If a calf had not consumed a minimum of $2 \mathrm{~L}$ at each of the 6 proceeding 12 -h checkpoints, barn staff would show the calf to the feeder again, following the same protocol as above. Once they consumed $2 \mathrm{~L}$ on their own, calves were left alone and not trained on the feeder again.

\section{Experimental Treatments}

The steel bar stall design was constructed of steel bars and was the original feeder in the facility (see Figure 1a). Stall dimensions were $93.98 \mathrm{~cm}$ in length, $36.83 \mathrm{~cm}$ wide (rear opening), and $83.82 \mathrm{~cm}$ from the ground to the top of the top rail. The solid side stall design used the same feeder but was adapted to fit over the existing feeder using dimensions from a commercial feeder that uses this stall design (see Figure 1b). The solid sides measured $124.46 \mathrm{~cm}$ in length, $36.83 \mathrm{~cm}$ wide, and $96.52 \mathrm{~cm}$ from the ground, with a $12.7 \mathrm{~cm}$ opening from the ground to the bottom of the stall. Solid side stalls were constructed from white $6.35-\mathrm{mm}-$ thick plastic board.

The type of stall treatment was switched every $2 \mathrm{wk}$ and was balanced between each of the 4 calf rooms. The stall designs remained in place until all calves being tested on that design had passed their 72 -h window of observation. Eighty calves were subjected to the solid side stall design, and 67 calves subjected to the steel bar style. Calves were assigned to a treatment based on which cohort they were born into. A cohort represented a group of calves that were tested on the same stall design within the same approximately 2 -wk window and in the same room; overall we used 17 cohorts of calves.

\section{Behavioral Analysis}

Following the initial training of each calf on the AMF, qualitative notes were recorded describing how willingly the calf entered the feeder and fed. The same person (T. R. Wilson) trained every calf and recorded these notes. The notes were later used to classify calves into 1 of 3 categories: easy, moderate, or difficult initial training. Notes included information about the ease of initial entry into the stall, ease of first use of the teat, and whether they took to the nipple quickly or whether they needed to be guided to the nipple repeatedly. Ease of entry was based on needing little to no push from behind or whether they needed to be pushed into the feeder and a tie used across the back of the feeder so the calf could not back out. Ease of use of the nipple was based on the amount of guidance needed to get the nipple into their mouth. A calf that required minimal guidance to the feeder, found the nipple with minimal assistance, and consumed their milk with minimal breaks off the nipple warranted an easy training score. A training session that required the calf to be led into the feeder as well as well as pushed from behind, had to be guided to the nipple several times, and took a long time to consume $2 \mathrm{~L}$ warranted a difficult training score. Calves between one extreme and the other were scored as moderate. For example, a calf that required a couple of attempts before latching onto the nipple and required an encouraging hand to push them into the feeder, but then drank their milk with only short breaks in feeding would warrant a moderate score. Another example scored as moderate would be a calf that entered the feeder with minimal assistance and took to the nipple quickly, but then had to be encouraged back to the nipple after several repeated breaks off the nipple.

Video cameras (SDR h85, Panasonic, Osaka, Japan) were mounted approximately $1.5 \mathrm{~m}$ above and facing the front of the AMF to record calf behavior. Calves were marked with colored livestock spray marker as well as a collar, which was color-coded so that calves would be easily distinguishable on camera. To be able to easily observe and identify calves during night hours, a red light was hung over the feeding area and on during dark hours from 0400 to $2100 \mathrm{~h}$.

Once introduced to the AMF, continuous recording took place for the next $72 \mathrm{~h}$. All behavioral observations were coded by one individual using Observer Software (version XT 12; Noldus Information Technology, Wa- 
geningen, the Netherlands). The observation window began after the calf had left the feeder for a minimum of 2 min after training. Outcome behaviors observed using the software are described in an ethogram in Table 1 .

Intraobserver reliability scoring was performed using the observer software. A total of $96 \mathrm{~h}$ and $8 \mathrm{~min}$ of video was analyzed a second time. The program then compared the 2 analyses and generated a kappa, or a measure of agreement beyond chance. With a tolerance of $5 \mathrm{~s}$ allowed, an overall average kappa score of 0.74 $(95 \%$ CI $=0.67-0.80)$ was obtained. This is considered substantial agreement (Dohoo, 2009).

\section{Feeding Data}

Feeding data were extracted from the software on the milk feeder (1 feeder for 2 rooms), with both feeders controlled by a single computer (CF 1000+ CS Combi; DeLaval Inc., Tumba, Sweden). Data collection began after the calf left the feeder after initial training and included the total amount of milk consumed in $72 \mathrm{~h}$, total time spent in the feeder, and total time spent feeding (see Table 1) within the 72-h observation period. Latency to first voluntary visit (time from training to calf entering the feeder and having its ear tag read) and latency to first voluntary feeding (time from training to first milk meal of any amount, where the calf entered the feeder without any assistance) were also collected from feeder data, but verified with video observation.

\section{Statistical Analyses}

A total of 147 calves were trained for our study. To be included, calves needed to have been able to stand and drink from a bottle and be healthy (i.e., not have been identified by staff as having any noticeable health problems). Ultimately, data from 117 of the calves enrolled were used in statistical analysis. Calves for whom the camera had failed $(\mathrm{n}=10)$ or the feeder was not working (i.e., not recording properly, mixer broke, not calibrated; $\mathrm{n}=18$ ), or calves that did not enter the feeder on their own within $72 \mathrm{~h}(\mathrm{n}=1)$, were not included in the statistical analyses. Many of the calves that were not included in the analysis were assigned to the steel bar design, hence the difference in treatment numbers. Another calf was not included in analyses because it was in a cohort of 1 calf after stall change. Of the 117 calves used, 65 were male and 52 were female. A total of 10 calves were treated for minor ailments (i.e., mild diarrhea) and medications used were either Metacam (Boehringer Ltd., Burlington, ON, Canada), Anafen (Merial Canada Inc., Baie d'Urfé, QC, Canada), Nuflor (Merck Animal Health Intervet, Kirkland, QC, Canada), Calflyte (Vetoquinol Inc., Lavaltrie, QC, Canada), Borgal (Merck Animal Health Intervet), or some combination of those. A univariate analysis was run to check the residuals of all outcomes; as data from these calves did not appear to be outliers, they were included in analysis. Data were used for a total of 57 (34 male, 23 female) calves on the steel bar stall design and 60 (31 male, 29 female) calves on the solid side stall design. For difficulty of training, 49 (29 female, 20 male) calves were categorized as easy, 45 (23 female, 22 male) as moderate, and 23 (13 female, 10 male) as difficult. Within the easy-to-train calves, 23 were trained on steel bar style, 26 on the solid style; for moderate calves, 24 were trained on steel bar, 21 on solid style; for difficult calves, 10 were trained on steel bar and 13 on solid style.

All statistical analyses were performed using SAS 9.4 (SAS Institute Inc., Cary, NC) using calf as the unit of observation but accounting for pen-level (group)

Table 1. An ethogram for behaviors recorded from video observations (1 to 4$)$ and from automatic milk feeder (AMF) computer data (5 and 6$)^{1}$

\begin{tabular}{lll}
\hline Item & Behavior & Description \\
\hline 1 & Time exploring stall & $\begin{array}{l}\text { Total time spent sniffing, licking, biting, or performing mouthing behavior toward the stall itself. } \\
\text { This includes the calf being outside the feeder or just in the feeder so its head is behind the ear tag } \\
\text { reader. }\end{array}$ \\
2 & $\begin{array}{l}\text { Total time spent sniffing with their head at or in front of the ear tag reader. } \\
\text { Total time spent licking with tongue or biting with teeth in contact with any part of the stall or } \\
\text { milk feeder, and its head is at or in front of the ear tag reader. }\end{array}$ \\
4 & Time licking or biting & $\begin{array}{l}\text { Number of times in the 72-h observation period the calf had to be brought into the feeder by a } \\
\text { human. }\end{array}$ \\
5 & Total time spent in feeder & $\begin{array}{l}\text { Recorded automatically by the AMF as total time the calf's RFID }{ }^{2} \text { was registered as present, in } \\
\text { the feeding stall. } \\
\text { Recorded automatically by the AMF as total time the calf's RFID was registered as present, in the } \\
\text { feeding stall with milk being sucked through the teat. }\end{array}$ \\
\hline
\end{tabular}

${ }^{1} 1$ and 2 were modified from Jensen et al. (1999) and Endres et al. (2005). Also recorded latency from training to first instance of behaviors 1 , 2 , and 3 .

${ }^{2} \mathrm{RFID}=$ radio-frequency identification. 
randomization with a random $($ room $\times$ stall $\times$ cohort $)$ term in the model.

General linear mixed models were used to evaluate associations between stall design, sex, group size, mean age of the group, and difficulty of training on the outcome variables: time from training to first voluntary stall exploration, time to first voluntary bite/ mouthing at the nipple, total amount of milk consumed over $72 \mathrm{~h}$, total time spent in the feeder over $72 \mathrm{~h}$, total time spent drinking, latency to first visit (where the ear tag registered on the feeder), and latency to first drink (where calf first voluntarily consumed milk). Each of these outcomes was analyzed as the number of hours from when the calf left the feeder after training to the first time the event occurred. Random effects of room $\times$ stall $\times$ cohort were included for all of the outcomes. Seventeen cohorts of calves were tested on the same stall design within the same approximately 2 -wk window in the same room. Nine cohorts of calves were trained on the solid design and 8 cohorts on the steel bar design, ranging from a minimum cohort size of 3 to a maximum of 20. Each model was first run with the variables stall design, difficulty of training, sex, and group size, as well as all possible interactions and were reduced if they were not near significance $(P>0.10)$. Significance was defined as $P \leq 0.05$. Group size was categorized as either small if there were 2 to 7 calves, or large if there were 8 to 16 calves. This was chosen based on previous studies that looked at group size and its association with feeding behavior (Jensen and Budde, 2006 ), their health and growth rate (Svensson and Liberg, 2006), and age at introduction (Jensen, 2007), and were adapted based on the fact that the facility had a maximum group size of 16 animals per pen.

For continuous outcomes, time from training to first voluntary stall explore, first bite at nipple, amount of milk consumed over $72 \mathrm{~h}$, time spent in the feeder, time spent drinking, latency to first visit, and first voluntary drink, the distribution of the residuals for models with treatment as the predictor were examined graphically. These were not normal and the outcome variable was log-transformed for analysis for all variables except the amount of milk consumed over $72 \mathrm{~h}$. For all continuous variables except the total amount of time spent drinking, we noted an interaction between treatment (stall design) and the difficulty of training classification. Calf sex was not a significant covariate in any model.

The number of retraining sessions was a categorical variable, to a maximum of 6 sessions; therefore, a multivariable Poisson model was used. Stall design and difficulty of training were used as explanatory variables in the model, and we found no significant interaction between them. A random effect of room $\times$ stall $\times$ cohort was included.

\section{RESULTS}

A descriptive summary of calf-level variables can be found in Table 2. All of the 117 calves included in statistical analyses performed at least 1 voluntary visit and voluntarily consumed milk within the 72-h observation window.

Of the 117 calves studied, 19 calves learned to use the feeder after just the initial training. Different numbers of calves took longer to successfully learn to use the feeder; $39,25,15,11,6$, and 2 calves required 1,2 , $3,4,5$, and 6 retraining sessions, respectively, beyond the initial training at first introduction. Stall design did not affect the number of retraining sessions calves received after the initial training and within the 72-h observation period. We noted an effect $(P=0.039$; df $=1,110)$ of sex in this model, as males required 1.33 times less retraining sessions than females; there were no interactions with other variables.

For the outcome of the time from training to first voluntary stall exploration, we observed an interaction $(P=0.046 ; \mathrm{df}=2,94)$ between the 2 variables stall design and difficulty of training. No effect of stall design was noted among calves that were easy or difficult to train, but among calves that were moderately difficult to train we found a difference between stall design $(P$ $<0.001, \mathrm{df}=2,94)$ in the amount of time it took after training for these calves to approach and explore the stall (Figure 3), with those on the steel bar stall taking more time than those on the solid side stall. Easy-totrain calves took on average 2.31 and $1.50 \mathrm{~h}$ on the steel bar and solid side stall design, respectively. Difficult calves took, on average, 6.72 and $7.41 \mathrm{~h}$ on the steel bar and solid side stalls, respectively. Calves classified as moderately difficult to train took an average of 5.44 $\mathrm{h}$ on the steel bar stall versus an average of $0.80 \mathrm{~h}$ on the solid side stall. Overall, moderately difficult calves trained on the steel bar style took 6.80 times longer $(95 \% \mathrm{CI}=2.38-19.42)$ than calves trained on the solid $\mathrm{AMF}$

For the time from training to first voluntary bite at the nipple, we noted an interaction $(P=0.06$; $\mathrm{df}=2$, 94 ) between the 2 variables stall design and difficulty of training. There was no effect of stall design among calves that were easy or difficult to train, but among calves that were moderately easy to train those on the steel bar style took 2.2 times longer $(95 \% \mathrm{CI}=$ 1.30-3.67) than calves on the solid AMF $(P=0.0034$, $\mathrm{df}=2,94)$. Calves classified as moderately difficult to train took an average of $18.21 \mathrm{~h}$ on the steel bar stall versus an average of $8.32 \mathrm{~h}$ on the solid side stall.

Stall design did not affect $(P=0.56$; $\mathrm{df}=1,94)$ the latency to first voluntary visit to the AMF. The effect of difficulty of training was significant $(P=0.04$; $\mathrm{df}=$ 


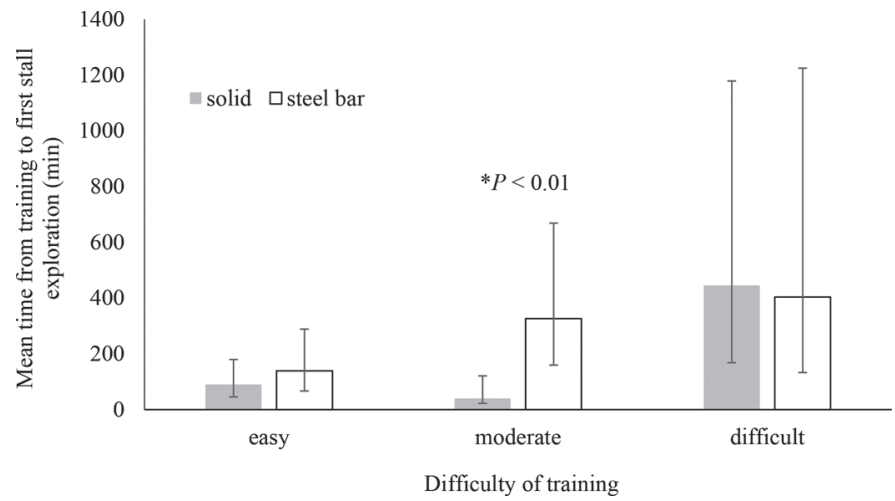

Figure 3. Time taken after initial training for calves to return and explore the feeder. Calves are compared within a category based on their difficulty of training score. There were 49 calves scored as easy (26 solid, 23 steel bar), 45 scored as moderate (21 solid, 24 steel bar), and 23 scored as difficult (13 solid, 10 steel bar). Confidence intervals are represented as the error bars in this graph.

$2,94)$, but we found no interaction $(P=0.19$, df $=2$, 94) with stall design.

For the latency to first voluntary drink, we noted an interaction $(P=0.02$; df $=2,94)$ between stall design and difficulty of training. There was no effect of stall design among calves that were easy or difficult to train, but among calves that were moderately easy to train we observed a difference $(P<0.001$, df $=2$, 94 ) in the amount of time it took calves to voluntarily enter and drink from the feeder after their first training session (Figure 4). Easy-to-train calves took, on average, 15.72 and $14.72 \mathrm{~h}$ on the steel bar and solid side stall design, respectively. Difficult calves took, on average, 23.67 and $23.59 \mathrm{~h}$ on the steel bar and solid side stalls, respectively. Calves classified as moderately difficult to train took an average of $23.78 \mathrm{~h}$ on the steel

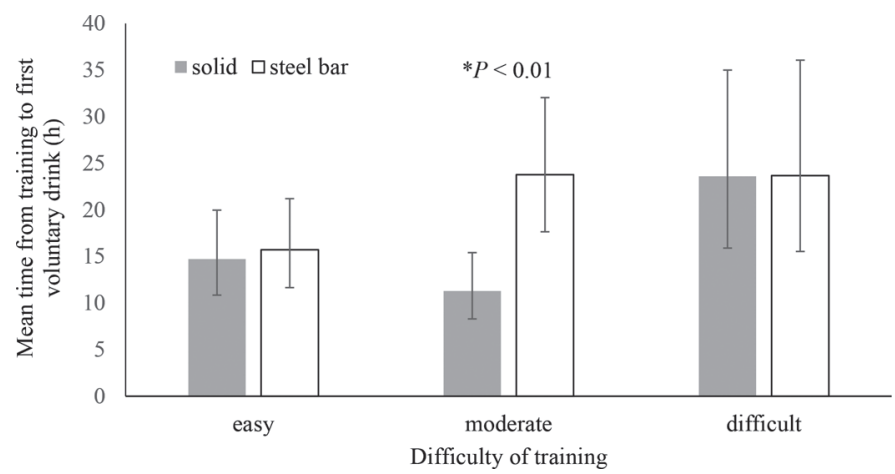

Figure 4. Time for calves to first voluntarily drink from the automated milk feeder (AMF) after their initial training session. Calves are compared within an AMF design based on their difficulty of training score. There were 49 calves scored as easy ( 26 solid, 23 steel bar), 45 scored as moderate (21 solid, 24 steel bar), and 23 scored as difficult (13 solid, 10 steel bar). Confidence intervals are represented as the error bars in this graph.

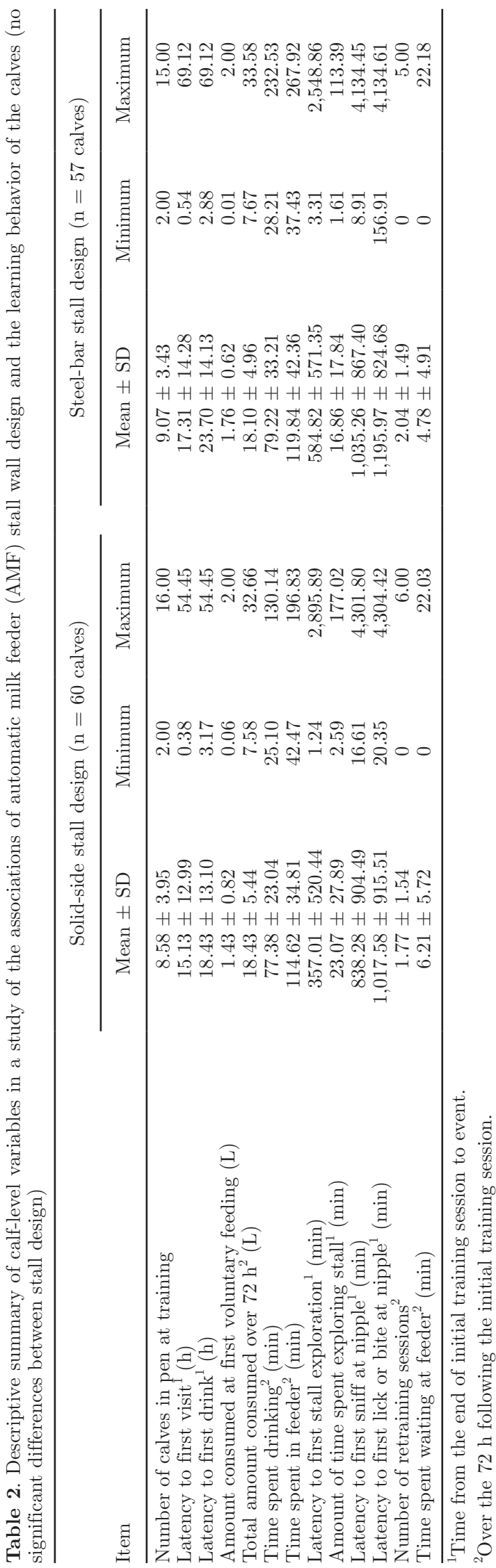

Journal of Dairy Science Vol. 101 No. 6, 2018 
bar stall versus an average of $11.30 \mathrm{~h}$ on the solid side stall. Overall, moderately difficult calves on the solid AMF drank voluntarily 2.1 times sooner $(95 \%$ CI $=$ 1.37-3.23) than calves on the steel bar AMF.

For the total amount of time spent in the feeder, we noted an interaction $(P=0.027$; $\mathrm{df}=2,92)$ between stall design and difficulty of training; however, no differences in the simple pairwise comparisons were detected. There was a significant effect of group size $(P$ $=0.038 ; \mathrm{df}=1,92)$ on the amount of time spent in the feeder. Calves trained in groups of 8 to 16 calves spent 1.15 times less $(95 \% \mathrm{CI}=0.77-0.99)$ time in the feeder than calves trained groups of 2 to 7 calves. We observed a correlation between group size and mean age of the group $(r=0.55)$; however mean age was not significant in the model, did not confound with any variables, and did not improve the fit of the model based on the Akaike information criterion. Stall design did not affect $(P=0.96 ; \mathrm{df}=1,98)$ the total amount of time spent drinking from the AMF; we found no interactions with other explanatory variables.

Looking at the total amount of milk consumed in $72 \mathrm{~h}$, there was an interaction $(P=0.007 ; \mathrm{df}=2$, $94)$ between stall design and difficulty of training. We observed no effect of stall design among calves that were easy or difficult to train, but among calves that were moderately easy to train a tendency $(P=0.054$; $\mathrm{df}=2,94)$ in the total amount of milk consumed over the observation period was noted. Calves trained on the steel bar style drank $3.18 \mathrm{~L}$ less milk than calves trained on the solid AMF (95\% CI $=-6.42-0.05$ ). Moderate calves on the steel bar stall design consumed an average of $17.28 \mathrm{~L}(95 \% \mathrm{CI}=15.02-19.53)$ of milk within the first $72 \mathrm{~h}$ compared with $20.46 \mathrm{~L}$ (95\% CI = 18.14-22.78) on the solid side stall design.

\section{DISCUSSION}

We observed the exploratory behavior of calves and their learning to use an AMF in the first $72 \mathrm{~h}$ after introduction. Stall design by itself did not have huge effects on calves learning to use the AMF. However, when calves were categorized by how easily they entered and drank from the feeder in their initial training session, stall design showed a significant effect among calves of moderate difficulty of initial training. These categorizations may align with other aspects of individual differences in calves (e.g., temperament). All the conditional effects of stall design favored the solid side stall design. The steel bar stall design did not offer any advantage in any of the outcomes we tested.

With nearly a $12.5 \mathrm{~h}$ difference between the 2 stall designs in time to first voluntary feeding in $38 \%$ of calves (those ranked as moderately easy at initial training), this could have a real biological effect. Calves feeding voluntarily that much sooner from the solid design are able to drink when they are hungry and do not need to rely on producers returning to bring them back to the feeder, which could result in increased milk consumption earlier in life and could improve growth potential. This would also mean less work for the producer in terms of watching new calves and having to do subsequent training sessions after introduction. Perhaps because the rest of the group pen was constructed of the same type of steel bars, calves were less interested in exploring the steel bar feeder because it looked similar to other surroundings. Previous research has shown that calves, especially when housed together, will exhibit exploratory behavior in novel social environments (De Paula Vieira et al., 2012) and to novel types of feed (Costa et al., 2014). For calves on the solid side treatment, the plastic offers something novel for them to investigate; accordingly, they investigated the stall sooner than calves on the other treatment. As for the nearly $8 \mathrm{~h}$ difference in averages seen in the groups of calves that were easy versus difficult to train, this could potentially correlate to calf vigor. Perhaps this overall calf vigor should be assessed before introduction to the AMF so that calves that will not adapt well could be individually fed for longer periods.

The same effect was seen for the outcomes time to first stall exploration, time to first bite at the nipple, and amount of milk consumed. Calves that were moderately difficult to train and trained on the steel bar style stall design took more time to approach and first explore the feeder and first lick or bite at the nipple. There was no difference between stall design within groups scored as easy or difficult. The same was true for the total amount of milk consumed, with no differences within groups scored as easy or difficult to train.

The findings of our study failed to support the hypothesis that calves trained to use the AMF with steel bar stall design would learn to use the feeder faster than those trained on the solid side stall design. We thought that, by applying learning theory, calves may learn to use the feeder by observing each other (Gleitman et al., 2011; Costa et al., 2014; Miller-Cushon and DeVries, 2016). In fact, the opposite was seen in calves ranked as moderately easy to train. Perhaps easy-to-train calves were so eager to obtain milk that stall design did not affect the outcome, whereas difficult calves were so hesitant that the stall design did not have an effect and they were going to take longer no matter what. On a more general level, not specific to feeding motivation, some overarching component of individuality or temperament might be responsible for our findings. The responses of calves in our study could well reflect the responses of calves in other studies, responding 
to a novel environment (e.g., Webb et al., 2015). The study by Webb et al. (2015), and others, examined how learning in animals is affected by individual differences related to emotional reactivity and coping style. Further testing of the animals used in our study could have potentially helped to validate whether, specifically, the emotional reactivity (fearfulness) of the animals was linked to their learning to use the AMF.

Another possible explanation for calves learning to feed sooner after initial training with the solid sides could be related to distraction during training. With the steel bars allowing visual contact between calves, this may have distracted them during their initial training and inhibited their learning.

To allow for the possibility of observational learning, all calves in our study were introduced to the group pen when it had at least 1 other experienced calf (with experience using the feeder) present. Other researchers who have investigated the effect of group size on calves learning to use the feeder often found group size to have an effect. When calves are limit fed they tend to occupy the feeder for more time, creating competition (Borderas et al., 2009). Smaller group sizes usually means that calves are closer in age, thus helping to reduce competition (Færevik et al., 2010). Jensen (2007) found that calves took longer to adapt to the feeder as group size increased. This did not seem to be the case in our study, as only the amount of total time spent in the feeder was affected by group size, with calves in larger groups spending 0.87 times less time occupying the feeder overall compared with smaller groups.

Lidfors et al. (1994) found that bulls had more frequent and longer sucking bouts with their dam than heifer calves. In the current study, we had fairly equal numbers of heifers and bulls and were, therefore, able to compare sexes. The only outcome detected difference was the number of times a calf had to be retrained after introduction to the feeder. Female calves required on average 2.27 retraining sessions, where males only required 1.71 retraining sessions. It is possible that because male calves are generally larger than female calves, they may be experiencing more hunger and therefore a greater motivation to visit the feeder.

One aspect of the current study that could be expanded or improved would be the level of detail applied to categorizing calves as easy, moderate, or difficult. Various components of the classifying criteria could be quantified; for example, the precise time from the beginning of training to the calf sucking on the teat continuously and the number of times the calf pulled back off the teat and needed to be guided back to the teat.

Another limitation to our study was that the level of activity of calves was not monitored. de Passillé et al.
(2014) investigated whether the level of activity in the first $4 \mathrm{~d}$ of life, and how much time a calf spent standing versus lying down, would affect milk intake. Those authors found that those factors did not have an effect on milk intake; however, calves were younger than we used and were also individually housed. It would have been interesting to see if level of activity in a group pen had any correlation with milk intake.

From results of our study, it does not appear that the design of the stall on the feeder has a huge effect on learning behavior; however, this brings about questions of how other factors associated with the feeders may influence learning. Such questions include whether the flooring and entrance to the feeder and are flush or made of the same material, how some designs of the nipple force the calves to learn to flip the nipple upward before drinking, and so on. These factors are not just relevant for calves, but cows as well when considering technologies such as robotic milking parlors. Future studies should take these physical factors and how they could affect animal behavior into account.

\section{CONCLUSIONS}

The results of this study suggest that the design of the stall (solid versus steel bar) at an AMF has minimal effect on dairy calves learning to use these systems. Only for those calves that were moderately easy to train was an effect of stall design observed. Among those calves, a solid side stall design decreased the amount of time it takes after training for calves to first explore the stall, first lick or bite at the nipple, and first voluntarily drink from the feeder. Calves moderately difficult to train also consumed more milk compared with those trained with steel bar stall sides. Stall design is only one factor that may be associated with calves learning to use automatic milk feeders, and other determinants of success of use of this technology should be quantified.

\section{ACKNOWLEDGMENTS}

This research was funded by Dairy Farmers of Canada (Ottawa, ON, Canada) as part of the Dairy Research Cluster program as well as additional funding from Ontario Ministry of Agriculture, Food and Rural Affairs (OMAFRA, Guelph, ON, Canada). The authors thank the staff of the Research and Innovation Centre-Dairy Facility in Elora (ON, Canada) for their cooperation as well as all volunteers involved in this project.

\section{REFERENCES}

Abdelfattah, E. M., M. M. Karousa, D. C. Lay Jr., J. N. MarchantForde, and S. D. Eicher. 2018. Short communication: Effect of 
age at group housing on behavior, cortisol, health, and leukocyte differential counts of neonatal bull dairy calves. J. Dairy Sci. 101:596-602. https://doi.org/10.3168/jds.2017-12632.

Abramson, J. H. 2006. WINPEPI (PEPI-for-Windows): Computer programs for epidemiologists. Epidemiol. Perspect. Innov. 1:6.

Borderas, T. F., A. M. B. de Passillé, and J. Rushen. 2009. Feeding behavior of calves fed small or large amounts of milk. J. Dairy Sci. 92:2843-2852. https://doi.org/10.3168/jds.2008-1886.

Canadian Council on Animal Care. 2009. CCAC Guidelines on the Care and Use of Farm Animals in Teaching, Research and Testing, CCAC, Ottawa, Canada.

Costa, J. H. C., R. R. Daros, M. A. G. von Keyserlingk, and D. M. Weary. 2014. Complex social housing reduces food neophobia in dairy calves. J. Dairy Sci. 97:7804-7810. https://doi.org/10.3168/ jds.2014-8392.

de Passillé, A. M., M. Rabeyrin, and J. Rushen. 2014. Associations between milk intake and activity in the first days of a calf's life and later growth and health. Appl. Anim. Behav. Sci. 3970:1-6. https://doi.org/10.1016/j.applanim.2014.10.002.

De Paula Vieira, A., A. M. de Passillé, and D. M. Weary. 2012. Effects of the early social environment on behavioural responses of dairy calves to novel events. J. Dairy Sci. 95:5149-5155. https://doi.org/ 10.3168/jds.2011-5073.

DeLaval. 2016. Calf Feeder CF1000+. Accessed Dec. 14, 2016. http:// www.delaval.ca/-/Product-Information1/Feeding/Products Distribution/feeding-stations/DeLaval-calf-feeder-CF1000/.

Dohoo, I. 2009. Screening and diagnostic tests. Pages 96-98 in Veterinary Epidemiologic Research. 2nd ed. V.E.R. Inc., Charlottetown, Prince Edward Island, Canada.

Endres, M. I., T. J. DeVries, M. A. G. von Keyserlingk, and D. M. Weary. 2005. Short communication: Effect of feed barrier design on the behavior of loose housed lactating dairy cows. J. Dairy Sci. $88: 2377-2380$.

Færevik, G., M. B. Jensen, and K. E. Bøe. 2010. The effect of group composition and age on social behavior and competition in groups of weaned dairy calves. J. Dairy Sci. 93:4274-4279. https://doi .org/10.3168/jds.2010-3147.

Fujiwara, M., J. Rushen, and A. M. de Passillé. 2014. Dairy calves' adaptation to group housing with automated feeders. Appl. Anim. Behav. Sci. 158:1-7. https://doi.org/10.1016/j.applanim.2014.06 011 .

Gleitman, H., J. Gross, and D. Reisberg. 2011. Learning. Pages 258 298 in Psychology. 8th ed. W.W. Norton and Company Inc., New York, NY

Jensen, M. B. 2007. Age at introduction to the group affects dairy calves' use of a computer-controlled milk feeder. Appl. Anim. Behav. Sci. 107:22-31. https://doi.org/10.1016/j.applanim.2006.09 017 .
Jensen, M. B., and M. Budde. 2006. The effects of milk feeding method and group size on feeding behavior and cross sucking in group housed dairy calves. J. Dairy Sci. 89:4778-4783.

Jensen, M. B., A. M. de Passillé, M. A. G. von Keyserlingk, and J. Rushen. 2008. A barrier can reduce competition over teats in pair housed milk-fed calves. J. Dairy Sci. 91:1607-1613. https://doi .org/10.3168/jds.2007-0623.

Jensen, M. B., L. Munksgaard, L. Mogensen, and C. C. Krohn. 1999. Effects of housing in different social environments on open-field and social responses of female dairy calves. Acta. Agric. Scand. A Anim. Sci. 49:113-120.

Jorgensen, M. W., A. Adams-Progar, A. M. de Passillé, J. Rushen, S. M. Godden, H. Chester-Jones, and M. I. Endres. 2017. Factors associated with dairy calf health in automated feeding systems in the Upper Midwest United States. J. Dairy Sci. 100:5675-5686. https://doi.org/10.3168/jds.2016-12501.

Lely. 2016. Feeding, Calf Feeder. Accessed Dec. 20, 2016. https://www .lely.com/ca/en/solutions/feeding/calm.

Lidfors, L. M., P. Jensen, and B. Algers. 1994. Suckling in free ranging beef cattle-temporal pattern of suckling bouts and effects of age and sex. Ethology 98:321-332.

Medrano-Galarza, C., J. Rushen, A. M. de Passillé, A. Jones-Bitton, T. J. DeVries, S. J. LeBlanc, and D. B. Haley. 2017. A survey of management practices regarding manual and automated milk feeding systems for dairy calves in Canada. J. Dairy Sci. 100:68726884. https://doi.org/10.3168/jds.2016-12273.

Miller-Cushon, E. K., and T. J. DeVries. 2016. Effect of social housing on the development of feeding behavior and social feeding preferences of dairy calves. J. Dairy Sci. 99:1406-1417. https://doi.org/ 10.3168/jds.2015-9869.

Svensson, C., and P. Liberg. 2006. The effect of group size on health and growth rate of Swedish dairy calves housed in pens with automatic milk-feeders. Prev. Vet. Med. 73:43-53. https://doi.org/10 .1016/j.prevetmed.2005.08.021.

Vasseur, E., F. Borderas, R. I. Cue, D. Lefebvre, D. Pellerin, J. Rushen, K. M. Wade, and A. M. de Passillé. 2010. A survey of dairy calf management practices in Canada that affect animal welfare. J Dairy Sci. 93:1307-1315. https://doi.org/10.3168/jds.2009-2429.

Webb, L. E., C. G. van Reenen, M. B. Jensen, O. Schmitt, and E. A. M. Bokkers. 2015. Does temperament affect learning in calves? Appl. Anim. Behav. Sci. 165:33-39. https://doi.org/10.1016/j applanim.2015.01.013.

Weber, R., and B. Wechsler. 2001. Reduction in cross-sucking in calves by the use of a modified automatic teat feeder. Appl. Anim. Behav Sci. 72:215-223. 